\title{
Q-LIBRAS: um jogo educacional para estimular alunos surdos à aprendizagem de Química
}

\author{
Q-LIBRAS: an educational game to stimulate deaf students in Chemistry \\ learning \\ Q-LIBRAS: un juego educacional para estimular alumnos sordos al \\ aprendizaje de Química
}

\section{Kionnys Novaes Rocha}

Professor na Universidade Estadual do Maranhão/Centro de Estudos Superiores de Caxias, Caxias, Maranhão, Brasil.

kionnysnovaes@gmail.com

ORCID - https://orcid.org/0000-0002-1879-1424

\section{Nayron Morais Almeida}

Mestrando na Universidade Federal de Minas Gerais, Belo Horizonte, Minas Gerais, Brasil.

nayronmorais@gmail.com

ORCID - https://orcid.org/0000-0003-2176-9110

\section{Cecília Regina Galdino Soares}

Professora mestra no Instituto Federal de Educação, Ciência e Tecnologia do Maranhão, Caxias, Maranhão, Brasil.

cecilia.soares@ifma.edu.br

ORCID - https://orcid.org/0000-0002-0731-3435

\section{Luís Fernando Maia Santos Silva}

Professor doutor no Instituto Federal de Educação, Ciência e Tecnologia do Maranhão, Caxias, Maranhão, Brasil.

luis.maia@ifma.edu.br

ORCID - https://orcid.org/0000-0002-9388-6386

Recebido em 6 de junho de 2018

Aprovado em 11 de novembro de 2019

Publicado em 12 de dezembro de 2019

\section{RESUMO}

O ensino de Química, no contexto da surdez, apresenta metodologias, em sua grande maioria, exclusivamente pautadas no uso da Língua Portuguesa, sendo ínfimos os materiais e recursos didáticos que contemplam o conhecimento químico em LIBRAS. Nesse contexto, esta pesquisa tem como objetivos proporcionar a aprendizagem de conteúdos químicos a alunos surdos, por meio do desenvolvimento de um jogo para celulares chamado Q-LIBRAS, bem como auxiliar a assimilação destes conteúdos de forma atrativa e interativa, tanto entre alunos surdos como ouvintes. Desta forma, este trabalho consiste em uma pesquisa aplicada, de natureza qualitativa. $O$ jogo desenvolvido contempla 60 (sessenta) questões de Química. Em sua elaboração foi utilizada parte do código-fonte da Suíte VLibras, que consiste em um conjunto de ferramentas computacionais capazes de traduzir conteúdos digitais para LIBRAS. Posteriormente, 
será disponibilizado a escolas de ensino médio que tenham em seu corpo discente alunos surdos. Além disso, outras temáticas da Química poderão ser acrescentadas ao aplicativo, enriquecendo ainda mais o aprendizado dos alunos. Por fim, visando ainda a ampla difusão dos resultados e conhecimentos gerados por esta pesquisa, ressalta-se o intuito de disponibilizar o Q-LIBRAS por meio da Internet.

Palavras-chave: Aprendizagem de Química; Software educacional; Surdez.

\section{ABSTRACT}

The teaching of chemistry, in the Deaf education context, presents methodologies that are mostly based exclusively on the use of the Portuguese language, and the materials and didactic resources that comprise the chemical knowledge in LIBRAS are small. In this context, this research aims at assisting the learning of Chemistry content for deaf students through the development of a mobile game called Q-LIBRAS, as well as helping the assimilation of these contents in an attractive and interactive way, both among deaf and hearing students. Thus, this work consists of an applied research of qualitative nature. The game that was developed contains 60 (sixty) Chemistry questions, and uses the source code of VLibras Suite, which consists of a set of computational tools capable of translating digital contents to LIBRAS. The game will later be made available to high schools that have deaf students. Furthermore, other chemistry topics can be added to the app, enriching students' learning.

Keywords: Learning Chemistry; Educational Software; Deafness.

\section{RESUMEN}

En lo que se refiere a la enseñanza de Química en el contexto de la sordez, las metodologías se presentan, en su gran mayoría, exclusivamente basadas en el uso de la Lengua Portuguesa, donde los materiales y recursos didácticos que contienen el conocimiento químico en LIBRAS son escasos. En ese contexto, esta investigación tiene como objetivos posibilitar el aprendizaje de contenidos químicos a los alumnos sordos por medio del desarrollo de un juego para móviles llamado Q- LIBRAS, así como el favorecimiento de la asimilación de estos contenidos de forma atractiva e interactiva tanto entre alumnos sordos como oyentes. De esta manera, este trabajo consiste en una investigación aplicada, de naturaleza cualitativa. El juego desarrollado incluye 60 (sesenta) cuestiones de Química. En su elaboración se utilizó parte del código fuente de la Suite VLibras, que consiste en un conjunto de herramientas computacionales capaces de traducir contenidos digitales para LIBRAS. Posteriormente estará disponible a escuelas de enseñanza media cuyo alumnado contiene alumnos sordos. Además, podrán añadirse otras temáticas de Química en la aplicación, enriqueciendo aún más el aprendizaje de los alumnos. Por último, buscando aún la amplia difusión de los resultados y conocimientos generados por esta investigación, se resalta el propósito de poner a disposición el QLIBRAS por medio de la internet.

Palabras clave: Aprendizaje de Química; Software educacional; Sordez.

\section{Introdução}

A dificuldade dos alunos na compreensão de conceitos básicos da Química é uma realidade comum no ambiente escolar e leva-os, consequentemente, à falta de interesse 
no estudo da disciplina. Fatores como esse são objetos investigativos de diversas pesquisas, que buscam propor melhorias no processo de ensino e aprendizagem da área. Um dos principais fatores impulsionadores do insucesso do educando é a falta de material didático adequado e de metodologias que despertem seu interesse em participar ativamente do processo de aprendizagem.

Direcionando o olhar ao ensino de Química para alunos surdos, os problemas são ainda mais desafiadores. Acredita-se que o modelo escolar atual não contemple as necessidades nem as especificidades desse público (FERREIRA; NASCIMENTO, 2014). Comumente, presencia-se em sala de aula apenas a inserção dos alunos surdos, no entanto, estes permanecem exclusos da aprendizagem, pelo fato de as metodologias de ensino se apresentarem, em grande maioria, exclusivamente pautadas no uso da Língua Portuguesa, quando são ínfimos os materiais e recursos didáticos que contemplam o conhecimento químico em LIBRAS (Língua Brasileira de Sinais).

Nesse sentido, cabe destacar o alicerce constitucional da inclusão dos alunos com necessidades especiais. A partir da Constituição Federal de 1988, ficou evidente a educação como um direito de todos, assegurada por condições de acesso e permanência na escola; além do atendimento educacional especializado, que deve ocorrer preferencialmente na rede regular de ensino.

Posteriormente, a Lei de Diretrizes e Bases da Educação Nacional - LDBN oo 9.394/96 (BRASIL, 2002a) reforça esse direito, possibilitando o atendimento educacional especializado gratuito aos educandos. Com o objetivo de assegurar a inclusão escolar dos alunos com necessidades especiais, foi promulgada a Política Nacional de Educação Especial na Perspectiva da Educação Inclusiva (BRASIL, 2008). O documento destaca a importância da elaboração e organização de recursos pedagógicos que possibilitem a plena participação dos alunos, considerando suas especificidades. Esse processo educacional deve potencializar a formação dos estudantes em sua completude, visando à autonomia e independência no âmbito escolar e social.

A Lei Brasileira de Inclusão (BRASIL, 2015) ratifica outros documentos, promulgados no país, referentes à educação de pessoas com algum tipo de deficiência que são inclusas em escolas de ensino regular. No artigo 28, a lei recomenda às escolas inclusivas que o conteúdo e as aulas sejam oferecidos em LIBRAS, como primeira língua, e em português na modalidade escrita, para os alunos surdos. Sugere, ainda, que os materiais sejam oferecidos em LIBRAS e as práticas pedagógicas modificadas para 
http://dx.doi.org/10.5902/1984686X32977

atender os alunos com deficiência. Outro ponto a se destacar na lei, observado nos capítulos 18 e 30, respectivamente, é a incorporação, por parte das escolas, das tecnologias assistivas como ferramenta importante para a ampliação das habilidades dos estudantes, colaborando para sua permanência nos cursos das redes pública e privada.

As tecnologias assistivas podem ser entendidas como um conjunto de avanços tecnológicos que apontam para novas possibilidades de aprendizagem e caminhos que levam a uma maior autonomia e efetivação do processo de inclusão da pessoa com deficiência, tanto no que diz respeito aos aspectos relacionados à vida social quanto à escolar (ALVES, PEREIRA E VIANA, 2017).

É importante desenvolver, com base nas leis que amparam e legalizam a educação de pessoas com deficiência no país, recursos que estimulem alunos surdos a adquirir conhecimentos sobre disciplinas básicas, como a Química. É nesse contexto que as ferramentas tecnológicas apresentam grande influência na promoção do aprendizado, uma vez que a aquisição de conhecimento vai além dos limites físicos da sala de aula e da descentralização do professor como única fonte de informação (NICHELE; SCHLEMMER, 2014).

Diante dos aspectos apresentados, esta pesquisa justificou-se pela importância de incluir digitalmente as pessoas com necessidades específicas de surdez, em especial, para promover a aprendizagem de conteúdos químicos por meio de um jogo digital para dispositivos móveis, chamado Q-LIBRAS.

É importante ressaltar, com base em pesquisas realizadas em periódicos nacionais e internacionais, uma grande carência de softwares e aplicativos de Química para alunos surdos. Diante dessa lacuna, a idealização do Q-LIBRAS pode proporcionar significativas contribuições de aprendizado para esse público. Uma de suas contribuições educacionais é o desenvolvimento de aprendizagem individual e coletiva, visto que o jogo pode ser usado em sala de aula, tanto com alunos surdos quanto com ouvintes. Outro aspecto favorável do jogo é a portabilidade proporcionada pelos dispositivos móveis, o que permite a sua utilização em diversos lugares. Adicionalmente, também estimula a aprendizagem informal associada à autonomia e flexibilidade.

Segundo Fialho (2007), o aspecto lúdico, tão comum aos jogos, pode ser utilizado para facilitar a elaboração de conceitos, o reforço de conteúdos, a sociabilidade entre alunos, a criatividade e o espírito de competição e cooperação. Ao jogar, o indivíduo desperta em si o desejo de vitória, pois as competições e os desafios são situações que 
http://dx.doi.org/10.5902/1984686X32977

mexem com os impulsos. Portanto, o uso de jogos digitais no ambiente educacional revela-se uma poderosa ferramenta para compor o aparato pedagógico utilizado por docentes, visando garantir um maior envolvimento entre aluno e conhecimento.

Mais especificamente, estudos recentes comprovam que a utilização de jogos digitais como recursos didáticos possibilitam aos alunos surdos a efetivação da aprendizagem, visto que essas mídias são constituídas de variados recursos, entre esses: imagens, animações, vídeos, textos verbais e não verbais (SILVA, 2014).

Nesse contexto, a pesquisa teve como objetivos proporcionar a aprendizagem de conteúdos químicos de alunos surdos por meio do desenvolvimento de um jogo para celulares chamado Q-LIBRAS, bem como favorecer a assimilação desses conteúdos de forma atrativa e interativa, tanto entre alunos surdos como ouvintes. Para a elaboração do jogo, foi utilizada parte do código-fonte da Suíte VLibras, que consiste em um conjunto de ferramentas computacionais capazes de traduzir conteúdos digitais para LIBRAS. Visando ainda a ampla difusão dos resultados e conhecimentos gerados por esta pesquisa, ressalta-se o intuito de disponibilizar o jogo gratuitamente por meio da Internet.

Ao fim, destaca-se que os resultados gerados por esta pesquisa podem ser utilizados para avaliar a relevância dos jogos educacionais acessíveis no processo de aprendizagem de alunos surdos. Além disso, por ser um jogo capaz de atender tanto a alunos surdos como ouvintes, é importante mencionar que a utilização do jogo Q-LIBRAS no processo de aprendizagem pode contribuir para a integração entre os estudantes, uma vez que as experiências e desafios disponibilizados pelo jogo são comuns a todos.

\section{Metodologia}

Esta pesquisa caracteriza-se pelo desenvolvimento metodológico de natureza qualitativa, em que se faz análise sobre a influência do aspecto lúdico do jogo para estimular o aprendizado de Química. Configura-se, ainda, em uma pesquisa aplicada, por meio do desenvolvimento de um jogo para dispositivos móveis, que aborda conteúdos de Química em LIBRAS. O jogo contempla 60 (sessenta) questões de Química, sendo dez de cada um dos seguintes tópicos: metais, ametais, gases nobres, Hidrogênio, propriedades periódicas e ligações químicas. Ao jogar, o aluno deve responder a essas questões escolhendo a alternativa correta dentre quatro disponíveis.

O projeto e desenvolvimento do jogo Q-LIBRAS ocorreram no período compreendido entre maio e outubro de 2017. Primeiramente, foi conduzido um levantamento 
http://dx.doi.org/10.5902/1984686X32977

bibliográfico para delinear e compreender as diferentes contribuições de aplicativos voltados a alunos surdos no ensino e aprendizado de Química. Durante essa etapa, observou-se que são raros os jogos e recursos desenvolvidos com este intuito, o que ressalta ainda mais a importância dos resultados e ações obtidos a partir deste trabalho.

Um importante aspecto do jogo Q-LIBRAS é a utilização de LIBRAS para a apresentação das questões, bem como para interação com os alunos. Esse recurso foi disponibilizado com a utilização de um personagem animado em 3D, capaz de realizar os gestos em LIBRAS. Para implementar esse sistema, foi necessário realizar uma pesquisa nas principais lojas de aplicativos para dispositivos móveis, sites brasileiros de downloads e projetos de pesquisa de universidades. Findado esse levantamento, foi conduzida uma etapa de seleção, com o intuito de escolher uma aplicação cujos recursos pudessem ser reutilizados por este projeto. Por fim, a última etapa consiste no desenvolvimento do jogo Q-LIBRAS a partir dos recursos disponibilizados na aplicação selecionada.

Realizada a pesquisa, observou-se que os aplicativos V-Libras (www.vlibras.gov.br), ProDeaf (www.prodeaf.net) e Hand Talk (www.handtalk.me) apresentavam as características almejadas para implementação do jogo, visto que todos foram desenvolvidos para dispositivos móveis, e disponibilizados nas plataformas Android e iOS, além de apresentarem um avatar animado em 3D como intérprete da língua de sinais. Contudo, durante a etapa de seleção, foram percebidos critérios importantes a favor do aplicativo $V$-Libras, como o fato de ser um projeto oriundo de uma parceria entre o Ministério do Planejamento, por meio da Secretaria de Tecnologia da Informação (STI), e a Universidade Federal da Paraíba (UFPB), então disponibilizado como um software de código aberto, cujo licenciamento permite a reutilização por outros projetos. Além disso, a aplicação conta com uma suíte de ferramentas computacionais de código aberto capaz de traduzir conteúdos digitais (texto, áudio e vídeo) para LIBRAS e permite a definição de conteúdos customizados. No entanto, também, essa ferramenta requer conexão constante com a Internet, pois as traduções são realizadas em servidores remotos para depois serem enviadas aos dispositivos móveis.

Após a etapa de análise, o software $V$-Libras foi selecionado para integrar o projeto em discussão. Nesse caso, uma solicitação foi enviada à equipe desenvolvedora, junto ao Ministério de Planejamento, requisitando autorização para o download e uso do software neste projeto. 
http://dx.doi.org/10.5902/1984686X32977

$\mathrm{Na}$ fase de desenvolvimento, foi necessário o download do código-fonte associado ao software V-Libras, a fim de se efetuar as devidas customizações e inclusão de conteúdo. Nessa etapa, foram conduzidas alterações estruturais no funcionamento do avatar animado para que o jogo pudesse ser executado sem a necessidade de estar conectado à Internet. A solução encontrada para esse problema foi concluir a tradução completa do banco de questões e armazenar os gestos correspondentes a cada pergunta localmente.

A implementação das traduções e a confecção da interface e lógica de programação do jogo Q-LIBRAS foram realizadas através da ferramenta Unity. A Unity é uma engine de jogos 3D que se destaca pela alta portabilidade, havendo integração com as APls: Direct3D, OpenGL e OpenGL ES. É devido a esse grande número de APIs suportadas que os jogos desenvolvidos com a Unity podem ser executados nas plataformas Mac, Windows, Linux, Xbox, Android e iOS. Pretende-se fazer uso dessa característica para disponibilizar versões do Q-LIBRAS nos mais diversos sistemas operacionais e dispositivos.

Após a etapa de tradução e confecção, o banco de questões com as respectivas alternativas e respostas foi incorporado ao jogo. É importante destacar que a aplicação foi projetada para funcionar de maneira off-line, ou seja, não há a necessidade de conexão com a Internet para que os alunos joguem. Porém, uma vez que o dispositivo do usuário esteja conectado à rede mundial de computadores, o Q-LIBRAS entra em contato com servidores da aplicação e poderá realizar atualizações. Dessa forma, questões poderão ser corrigidas ou o banco de questões expandido, caso haja necessidade.

Como fase final desta pesquisa serão realizados testes com alunos surdos de Ensino Técnico, visando confirmar se o aplicativo cumpre com os objetivos propostos, como 0 estímulo ao aprendizado de Química de forma fácil e divertida. Concomitantemente a essa etapa, serão realizadas correções e eventuais ajustes antes de ser disponibilizado gratuitamente pela Internet.

\section{Resultados e Discussões}

De início, um dos grandes desafios no desenvolvimento do aplicativo foi a representação dos enunciados de Química em LIBRAS, levando em consideração as limitações de tamanho da tela de um celular e, principalmente, as especificidades dos alunos surdos, de forma que os conteúdos fossem exibidos com clareza e precisão. Essa 
http://dx.doi.org/10.5902/1984686X32977

problemática é raramente abordada na literatura porque a maioria dos softwares e aplicativos não disponibiliza suporte a línguas de sinais. Portanto, estas aplicações traduzem seu conteúdo apenas substituindo os textos exibidos na tela por versões em outras línguas. Assim, a necessidade de traduzir textos para alguma língua de sinais, como LIBRAS, requer a inclusão de novos componentes e recursos visuais voltados ao usuário surdo.

Nessa perspectiva, no início do projeto, pensou-se em representar o texto em LIBRAS por meio de vídeos, indexados ao software, nos quais uma intérprete sinalizaria os enunciados com as respectivas opções de respostas, porém essa opção possui claras desvantagens. De acordo com os estudos de Amaral (2012), o alto custo é um exemplo de desvantagem uma vez que são necessários instrumentos adequados, como câmera de vídeo, ambiente apropriado para gravação, além de custos associados a produção e edição. Outro fator que também deve ser levado em consideração é a manutenção do vídeo produzido, pois a sinalização é realizada por uma mesma pessoa, e deve seguir uma linearidade em roupas e cenário. Assim, qualquer alteração no conteúdo implicaria em novas gravações, aumentando o trabalho e os custos, o que culmina na inviabilização do projeto e de possíveis expansões no banco de questões.

Dessa forma, optou-se pelo uso de um agente virtual sinalizador, ou avatar, que é um modelo tridimensional representando uma figura humana que sinaliza a linguagem em LIBRAS (AMARAL, 2012). A utilização do avatar possui inúmeras vantagens, como a produção de conteúdo, que ocorre em tempo real, podendo ser modificado a qualquer momento e o fato de ocupar pouco espaço no dispositivo, permitindo que a aplicação final fique bastante compacta. Como principal desvantagem no uso do avatar há a falta de naturalidade e expressão facial na execução de alguns gestos.

A representação gráfica do jogo demonstra-se compatível com as necessidades dos estudantes com surdez, por explorar imagens coloridas, um aspecto que faz parte das estratégias associadas à aprendizagem dos surdos. Em consonância com o trabalho de Hildebrand (2016), que aborda os jogos eletrônicos no processo de cognição dos surdos, os jogos adaptados que fazem uso de cores em lugar de sons conquistaram a atenção do público-alvo, refletindo, assim, sobre a importância das tecnologias no contexto da surdez.

Quanto a esse aparato tecnológico para alunos surdos em Química, notam-se poucas contribuições na área no que se refere ao desenvolvimento e adaptação de softwares específicos. Em pesquisas realizadas nas bases de dados dos periódicos 
http://dx.doi.org/10.5902/1984686X32977

CAPES, SciELO, no período de maio a outubro de 2017, foram verificados trabalhos sugestivos de várias ferramentas tecnológicas de Química, que podem ser direcionadas a alunos surdos, entre eles, destacam-se os jogos "Imagens e nomes dos elementos químicos", que tem como objetivo associar a figura ao elemento químico correspondente; "Jogos de Química Ambiental - Química Básica”, baseado em perguntas e respostas; "Roleta Química", que aborda os tipos de ligações químicas; "Adivinhas sobre a Tabela Periódica", que possibilita conhecer alguns elementos e suas respectivas funções; "Borboletas Químicas", no qual o jogador seleciona uma determinada borboleta de acordo com a pergunta realizada, abrangendo conteúdos relacionados aos elementos químicos, famílias e grupos; e "Descoberta dos pares", um jogo da memória online arquitetado com imagens de elementos químicos (TRESPACH; GUNTZEL; BEDIN, 2016).

Segundo os autores supracitados, esses jogos possibilitam eficácia no aprendizado dos conteúdos, devido à grande representatividade visual, essencial ao processo cognitivo e aprendizagem da pessoa com surdez. No entanto, é importante ressaltar que as ferramentas tecnológicas exploradas não foram desenvolvidas essencialmente ao público com surdez, pois não contemplam a tradução em LIBRAS, que é um fator relevante no processo de inclusão. Esses direitos linguísticos foram reconhecidos a partir da Lei nº. 10.436/2002 (BRASIL, 2002b), que preconiza a Língua Brasileira de Sinais como meio legítimo de comunicação entre os surdos, e devem ser priorizados no meio educacional como um importante instrumento de interação social, aprendizado formal e, sobretudo, de efetivação da inclusão de alunos com deficiência auditiva.

Diante desses aspectos, o aplicativo Q-LIBRAS contribui na difusão da língua de sinais no contexto da Química e pode incentivar a produção de novas tecnologias educacionais voltadas aos estudantes com surdez.

Tendo em vista essas considerações, o aplicativo pode proporcionar a assimilação de conteúdos fundamentais de Química de forma atrativa e lúdica. As questões estão relacionadas à Tabela Periódica, cujos elementos se classificam em metais, ametais, gases nobres e Hidrogênio, de acordo com as propriedades dos elementos constituintes de cada grupo; assim, contém dez questões referentes a cada grupo citado. Nas perguntas, explora-se a classificação dos elementos, seus processos de obtenção, suas características, bem como aplicabilidades e os impactos que podem ocorrer ao meio ambiente, como é o caso dos metais pesados. Exemplificando a sistemática do jogo, a Figura 1 mostra uma pergunta relacionada aos metais. 
Figura 1 - Na tela de perguntas o aluno pode escolher uma resposta ou solicitar a exibição do texto em LIBRAS

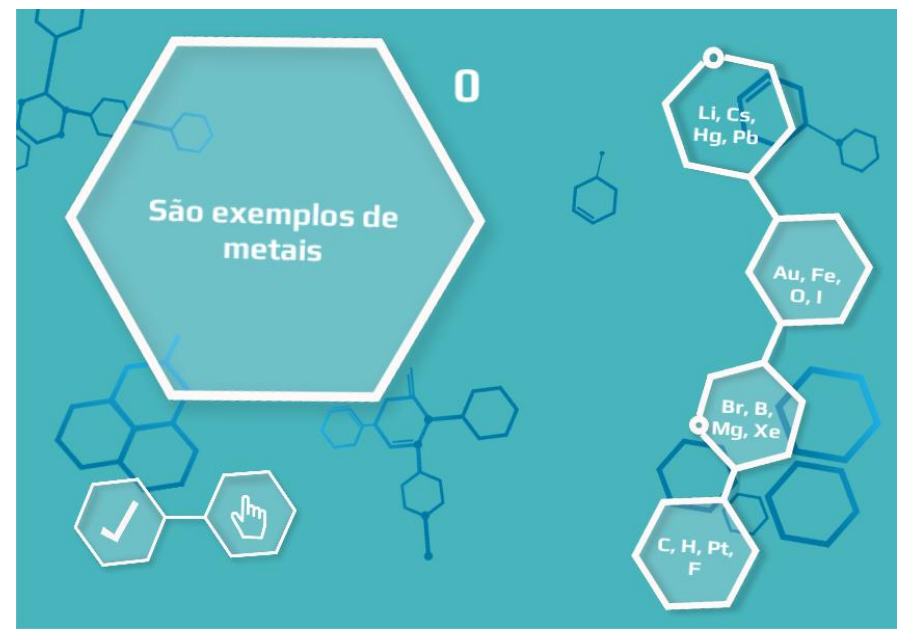

Fonte: Produção dos autores.

No exemplo mostrado, o objetivo é que o aluno identifique os elementos classificados como metais, deslocando o grupo correspondente até a figura da "mãozinha", por meio da tecnologia touchscreen. Adicionalmente, o aluno é estimulado a ter familiaridade com a representação simbólica dos elementos químicos.

Caso o aluno faça a identificação correta, o fundo da tela ficará na cor verde, e o avatar indicará em LIBRAS o acerto, como mostra a Figura 2 abaixo. Nesse caso, o avatar sinaliza os parabéns, servindo como reforço positivo para que o aluno mantenha 0 bom desempenho nas próximas questões.

Figura 2 - Imagem da tela de acerto. O aluno é parabenizado também em LIBRAS

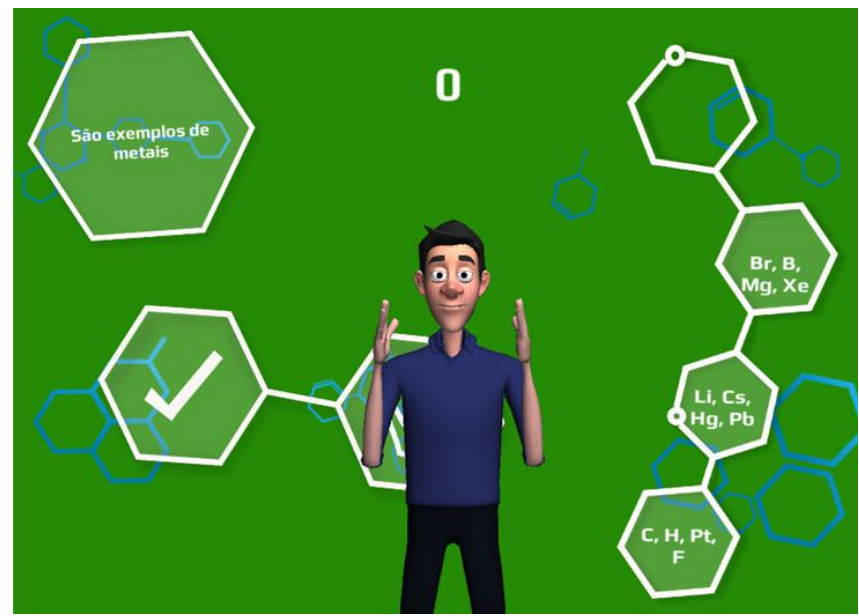

Fonte: Produção dos autores. 
Todavia, se a resposta for incorreta, a cor da tela será vermelha, seguida da sinalização do erro pelo avatar (Figura 3). É importante destacar que o aluno não sofre penalidades quando responde uma questão errada. Nestes casos, o jogo exibe uma nova pergunta, sem exibir a resposta correta para a questão marcada erroneamente; assim, em jogadas futuras, o aluno pode relembrar o erro e buscar uma nova solução.

Figura 3 - Imagem da tela de erro. O aluno também recebe estímulo por meio de cores

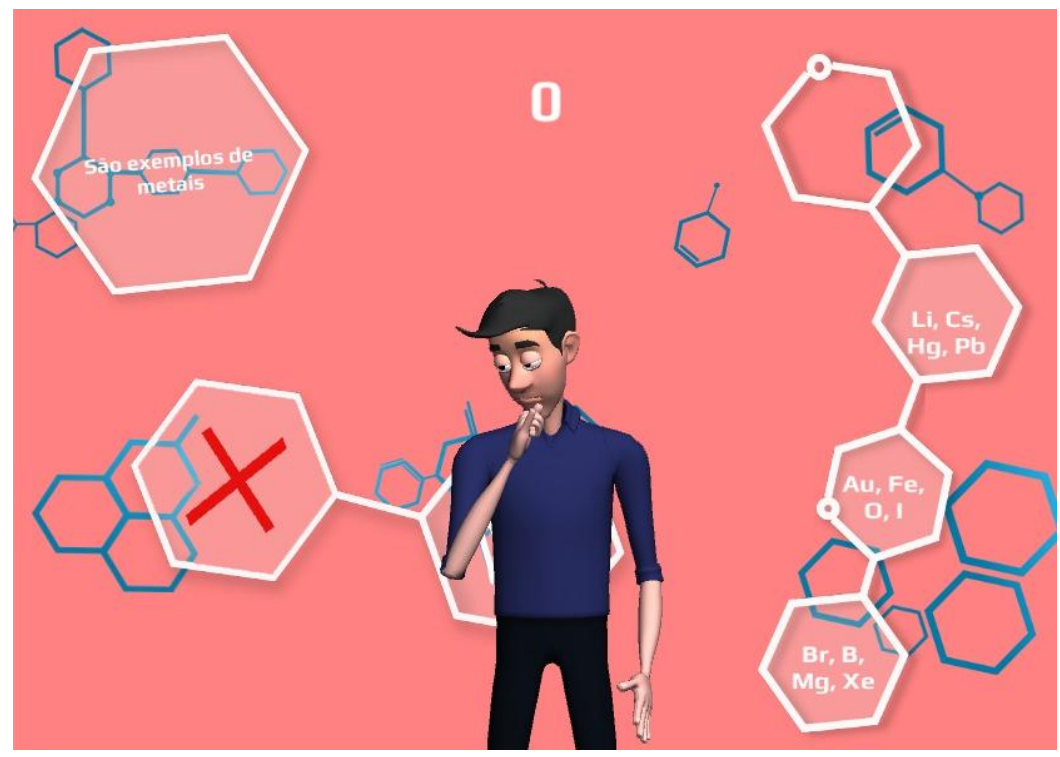

Fonte: Produção dos autores.

Destaca-se, também, a importância das cores como ferramenta para o aprendizado da pessoa com surdez. Como enfatizam Júnior, Domiciano e Henriques (2016), a cor é um dos parâmetros mais importantes em um layout, demonstrando personalidade e reforçando a compreensão das mensagens. Com isso, o fundo da tela foi programado para mudar de cor de acordo com a resposta dada pelo aluno.

O aplicativo do Q-LIBRAS conta, ainda, com um sistema de pontuação que funciona como um ranking pessoal. A cada execução do jogo o aluno sente-se desafiado a melhorar o seu desempenho, realizando pontuações maiores que as registradas anteriormente.

Além de perguntas relacionadas à Tabela Periódica, seus elementos e propriedades, também há dez questões sobre ligações químicas. Os conteúdos abordados são fundamentais na disciplina de Química, geralmente trabalhados no primeiro ano do ensino médio, ainda assim, o aplicativo pode ser utilizado também por alunos do segundo e terceiro anos, considerando que os tópicos são pré-requisito ao estudo de outros conteúdos. 
Nesse intuito, o jogo Q-LIBRAS poderá ser trabalhado no âmbito da sala de aula como auxílio de aprendizagem em Química, tanto para alunos surdos quanto para ouvintes, bem como para reforço na aprendizagem de sinais em LIBRAS. Tendo em vista essa finalidade, um importante recurso adotado é o controle na velocidade na sinalização pelo avatar (Figura 4), que pode ser ajustado para reproduzir os sinais na velocidade adequada a cada aluno.

Figura 4 - O jogo permite que o aluno ajuste a velocidade em que são exibidos os sinais em LIBRAS

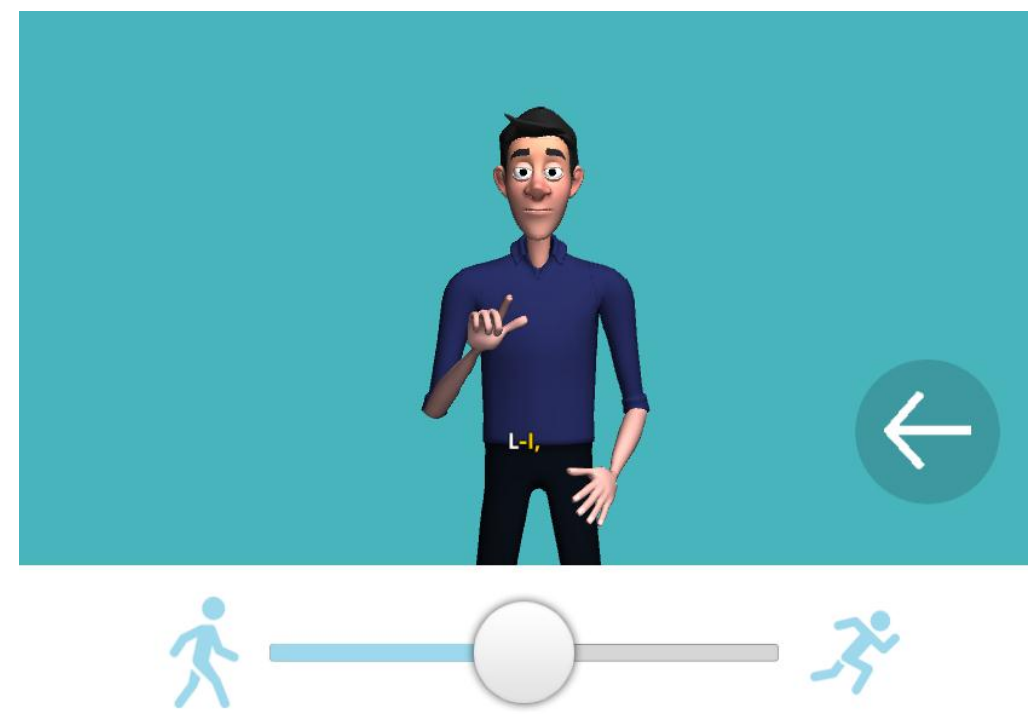

Fonte: Produção dos autores.

\section{Considerações finais}

A utilização de ferramentas tecnológicas na educação proporciona um elo entre o ensino e a aprendizagem, rompendo o tradicionalismo centrado no professor, que é baseado somente na exposição de conteúdos. De uma forma geral, pesquisas constantemente relatam esse fato, apresentam reflexões e propostas que objetivam atrair os alunos ao estudo de determinada disciplina, entretanto, no que se refere ao ensino de Química no contexto da surdez, existem grandes desafios, visto que há grande carência de recursos que auxiliem o professor no ensino. Além disso, há ainda os obstáculos epistemológicos do professor frente a esses desafios, atrelados a sua formação na perspectiva da Educação Inclusiva.

Diante disso, o aplicativo Q-LIBRAS apresenta-se oportuno para que alunos surdos estudem Química e adquiram características de autonomia em seu aprendizado. Porém, é 
http://dx.doi.org/10.5902/1984686X32977

importante salientar que o professor é o mediador da construção do conhecimento, é um elemento fundamental para a condução do aluno rumo ao aprendizado.

É relevante, novamente, ressaltar a continuidade da pesquisa com o jogo QLIBRAS, a fim de aprimorá-lo por meio de testes com o público-alvo, para que, posteriormente, seja disponibilizado para as escolas inclusivas, nas quais estão os alunos surdos. Outro ponto importante a ser destacado é que, devido à forma que foi desenvolvido, poderão ser acrescentados ao Q-LIBRAS outros assuntos de Química, enriquecendo ainda mais o jogo e aumentando as possibilidades do ensino e aprendizagem dos alunos surdos e também ouvintes, dentro de uma perspectiva de educação mais inclusiva.

Por fim, a opção de utilizar softwares com código aberto e de licença livre, bem como a disponibilização do aplicativo gratuitamente na Internet, visam facilitar a difusão das tecnologias e métodos empregados no desenvolvimento do Q-LIBRAS. Dessa forma, esperamos que este trabalho estimule o surgimento de mais jogos com viés inclusivo, e que, de maneira geral, recursos para inclusão de alunos surdos sejam disponibilizados em aplicativos e softwares populares.

\section{Referências}

ALVES, Maria Dolores Fortes; PEREIRA, Guilherme Vasconcelos; VIANA, Maria Aparecida Pereira; Tecnologia assistiva na perspectiva de educação inclusiva: o ciberespaço como lócus de autonomia e autoria. Laplage em Revista. Sorocaba, n.2, ago. 2017.Disponível em:

http://www.laplageemrevista.ufscar.br/index.php/lpg/article/view/347/491. Acesso em: 29 mai. 2018.

AMARAL, Wanessa Machado. Sistema de Transcrição da Língua Brasileira de Sinais Voltado à Produção de Conteúdo Sinalizado por Avatares 3D. Tese (Doutorado em Doutorado em Engenharia Elétrica) - Universidade Estadual de Campinas, 2012.

BRASIL, LEI № 13.146, DE 6 DE JULHO DE 2015. Dispõe sobre a Lei Brasileira de Inclusão da Pessoa com Deficiência. Disponível em:

http://www.planalto.gov.br/ccivil_03/_Ato2015-2018/2015/Lei/L13146.htm Acesso em: 06 jun. 2018.

BRASIL, LEI № 10.436, DE 24 DE ABRIL DE 2002(b). Dispõe sobre a Língua Brasileira de Sinais. Disponível em www.planalto.gov.br/.../2005/decreto/d5626.htm Acesso em 06 jun. 2018.

BRASIL. Congresso Nacional. Lei de Diretrizes e Bases da Educação Nacional. Lei no 9394/96. Brasília: Centro Gráfico, 2002(a). 
http://dx.doi.org/10.5902/1984686X32977

BRASIL. Política Nacional de Educação Especial na Perspectiva da Educação Inclusiva. Ministério da Educação, p. 19, 2008.

FIALHO, Neusa Nogueira. Jogos no Ensino de Química e Biologia. 1. ed. Curitiba: IBPEX, 2007.

FERREIRA, Wendel Menezes; NASCIMENTO, Sandra Patrícia de Faria. Utilização do jogo de tabuleiro - ludo - no processo de avaliação da aprendizagem de alunos surdos. QNESC, v. 36, p. 28-36, 2014.

HILDEBRAND, Hermes Renato. OS JOGOS ELETRÔNICOS NO PROCESSO DE COGNIÇÃO DE SURDOS. Journal of Research in Special Educational Needs. Lisboa, n. 1, ago. 2016. Disponível em: https://onlinelibrary.wiley.com/doi/full/10.1111/14713802.12218 Acesso em: 13 jul. 2017.

JÚNIOR, Marcos Airton Morasco; DOMICIANO, Cassia Leticia Carrara; HENRIQUES, Fernanda. Diretrizes acessíveis em ambientes digitais: Aplicação de parâmetros gráfico-inclusivos para o desenvolvimento de sites. Ergodesign e $\mathrm{HCl}$, v. 4, p. 65-73, 2016.

NICHELE, Aline Grunewald; SCHLEMMER, Eliane; Aplicativos para o ensino e aprendizagem de Química. CINTED- Novas Tecnologias na Educação, v. 12, p. 1-10, 2014.

SILVA, Emanuel Feliciano. Games: Um Start na Educação de Surdos. In: CINTEDI, 2014, Campina Grande. Anais CINTED. Campina Grande: Realize, 2014. Disponível em:http://editorarealize.com.br/revistas/cintedi/trabalhos/Modalidade_1datahora_14_11_2 014_23_51_14_idinscrito_4566_87b99c1bc60adfa8d170dcba544f69bb.pdf. Acesso em: 20 jun. $\overline{2} 01 \overline{7}$.

TRESPACH, Rúbia Raubach; GUNTZEL, Bruno; BEDIN, Everton. Análise química sobre ferramentas tecnológicas para ensinar química na Educação Básica à alunos surdos. Revista Tecné, Episteme y Didaxis: TED, p. 625-631, 2016.

\section{Correspondência}

Kionnys Novaes Rocha - Universidade Estadual do Maranhão/Centro de Estudos Superiores de Caxias, Praça Duque de Caxias, Morro do Alecrim, Caxias, Maranhão - Brasil.

CEP: $65604-380$

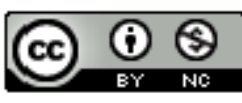

This work is licensed under a Creative Commons Attribution-NonCommercial 4.0 International (CC BY-NC 4.0) 